\title{
Platelet Count to Spleen Diameter Ratio as a Noninvasive Marker of Oesophageal Varices in Hepatic Cirrhosis
}

\author{
Bimal K. Agrawal ${ }^{1}$, Akash Garg${ }^{2}$, Himanshu Parashar³, Taniya Pruthi ${ }^{4}$, Shankar Tayal ${ }^{5}$ \\ ${ }^{1}$ Department of Medicine, MM Institute of Medical Sciences and Research, Maharishi Markandeshwar Deemed to be \\ University, Mullana, Haryana, India. ${ }^{2}$ Department of Medicine, MM Institute of Medical Sciences and Research, \\ Maharishi Markandeshwar Deemed to be University, Mullana, Haryana, India. ${ }^{3}$ Department of Medicine, MM Institute \\ of Medical Sciences and Research, Maharishi Markandeshwar Deemed to be University, Mullana, Haryana, India. \\ ${ }^{4}$ Department of Medicine, MM Institute of Medical Sciences and Research, Maharishi Markandeshwar Deemed to be \\ University, Mullana, Haryana, India. ${ }^{5}$ Department of Medicine, MM Institute of Medical Sciences and Research, \\ Maharishi Markandeshwar Deemed to be University, Mullana, Haryana, India.
}

\section{ABSTRACT}

\section{BACKGROUND}

Cirrhosis, a chronic liver disease is an important health problem. The common aetiological factors are hepatitis $\mathrm{B}$, hepatitis $\mathrm{C}$, alcohol consumption and nonalcoholic fatty liver disease. Oesophageal varices are an important complication of hepatic cirrhosis, its prevalence in a cirrhotic being nearly $80 \%$. Variceal haemorrhage can be fatal, and it has been recommended that every patient with cirrhosis should be screened for oesophageal varices at the time of presentation. This may not be feasible in resource crunch setting. There is a need for simpler methods which may help suspect or diagnose oesophageal varices. In this study platelet count to spleen diameter ratio, as has been suggestive in some studies, has been analysed to find out as to whether it can be used as a marker of presence of oesophageal varices.

\section{METHODS}

One hundred and fifty patients of cirrhosis of liver were included in this study. All patients underwent upper gastrointestinal endoscopy for the presence of oesophageal varices. Total platelet count (per cubic millimetre) to splenic diameter (in millimetre) ratio was calculated for each patient.

\section{RESULTS}

It was observed that there exists a correlation between the ratio of platelet count and bipolar spleen diameter for the prediction of oesophageal varices. A cut off value of $\mathrm{P} / \mathrm{S}$ ratio of 909 correlated well with the presence of varices. The subject with advanced disease as per Child Pugh classification had lower $\mathrm{P} / \mathrm{S}$ ratio.

\section{CONCLUSIONS}

Platelet count to spleen diameter ratio can be used as a sensitive marker for the prediction of oesophageal varices in patients with cirrhosis of liver.

\section{KEY WORDS}

Cirrhosis of Liver, Oesophageal Varices, Platelet Count, Spleen Diameter

\author{
Corresponding Author: \\ Dr. Bimal K. Agrawal, \\ Office of the Principal, \\ MM Institute of Medical Sciences and \\ Research, Mullana-133207, Ambala, \\ Haryana, India. \\ E-mail: onlybimal@gmail.com
}

DOI: $10.14260 /$ jemds/2019/744

Financial or Other Competing Interests: None.

How to Cite This Article:

Agrawal BK, Garg A, Parashar H, et al. Platelet count to spleen diameter ratio as a noninvasive marker of oesophageal varices in hepatic cirrhosis. J. Evolution Med. Dent. Sci. 2019;8(46):3432-3436, DOI: $10.14260 /$ jemds/2019/744

Submission 18-09-2019,

Peer Review 28-10-2019,

Acceptance 04-10-2019,

Published 18-11-2019. 


\section{BACKGROUND}

Cirrhosis, a chronic liver disease, is characterized by diffuse fibrosis and distortion of the normal acinar and/or lobular architecture of liver with or without degeneration, regeneration or nodule formation. ${ }^{1}$ Cirrhosis results in a decrease in hepatic cellular mass and studies have proven that cirrhosis is reversible when disturbances have been removed. In India, the aetiology of cirrhosis of the liver is varied, the most common infectious condition is HBV 2 (Hepatitis B Virus) infection followed by alcohol and hepatitis C infection. ${ }^{3}$ The prevalence of hepatitis B infection in India is $4.7 \%{ }^{4}$ Cirrhosis eventually leads to the development of portal hypertension which affects various organs of the body, causing morbidity and even deaths in some patients. Portal hypertension presents with ascites, gastrointestinal bleed and splenomegaly. Most dreaded complication of portal hypertension, oesophagal variceal bleeding, 5 is responsible for high mortality in cirrhotic patients.

Oesophagal varices have a high prevalence rate of 60 $80 \%$ in cirrhotic patients and it is a major cause of bleeding in $25-30 \%$ of the patients. Every year 5\% new cases of oesophagal varices are seen and every year, nearly $5-10 \%$ of these patients progress to large varices from small varices. Previous literature recommends that all cirrhotic patients should be screened for the presence of oesophagal varices at the time of diagnosis. However, performing an endoscopic evaluation of all cirrhotic patients for screening may not be the affordable approach, more so in resource crunch situations like India. A cost-effective method of screening would be possible if cirrhotic patients could be identified for varices based on clinical and biochemical variables. In this study, platelet count to spleen diameter (P/S ratio) has been evaluated as a single noninvasive test for prediction of oesophagal varices.

\section{METHODS}

The study protocol was approved by the Institutional Ethics Committee prior to enrolling any patient for the study. One hundred fifty patients of cirrhosis were included in the study fulfilling the inclusion and exclusion criteria. It is a prospective study of all patients consecutively diagnosed with cirrhosis of liver in a tertiary care hospital during the period November 2013 to August 2015 were included. All patients were subjected to platelet count estimation, spleen diameter and upper gastrointestinal endoscopy for oesophagal varices detection. Diagnosed subjects were graded according to Child-Pugh classification. ${ }^{1}$ Spleen diameter was obtained via USG abdomen in all subjects. Upper GI endoscopy performed in all subjects using STORZ Karl STORZ XENON 100 flexible endoscope. Oesophageal varices were graded according to Paquet grading and size classification. $\mathrm{P} / \mathrm{S}$ diameter ratio was calculated and correlated with the presence of oesophageal varices. A value of 909 for this ratio of $\mathrm{P} / \mathrm{S}$ diameter was considered as a cut off point for this study, as has been validated by Giannini et al.6 Extrahepatic or non-cirrhotic causes of oesophageal varices were excluded. The patient's undergone treatment like band ligation, sclerotherapy, trans-jugular intrahepatic portosystemic shunt were also excluded. Statistical analysis was done by using descriptive statistics (Mean, percentage and standard deviation) and inferential statistics using Chi square test, sensitivity, specificity, negative predictive value, positive predictive value.

\section{RESULTS}

In this study, the mean age of the subjects was $48.76 \pm 9.0$ years; the majority of subjects $(83 \%)$ were males. The maximum number of patients belonged to Child-Pugh Class B $(56.7 \%)$. Ascites and pedal oedema were the most frequent clinical presentation and most common sign encountered was splenomegaly (Table 1).

\begin{tabular}{|c|c|c|c|}
\hline Child-Pugh Classification & A & B & C \\
\hline No of subjects (N=150) & $15(10 \%)$ & $85(56.7 \%)$ & $50(33.3 \%)$ \\
\hline Icterus & 5 & 30 & 10 \\
\hline Pedal Oedema & 0 & 65 & 55 \\
\hline Ascites & 5 & 80 & 55 \\
\hline Splenomegaly & 0 & 55 & 35 \\
\hline Encephalopathy & 0 & 5 & 35 \\
\hline Table 1. Distribution of Subjects as Per Child-Pugh Classification \\
\hline
\end{tabular}

With advancing stage, a decrease in platelet count was observed and p-value for the correlation between child Pugh score and mean platelet count came out to be 0.027. A maximum number of patients belonged to Class $\mathrm{C}$ and maximum bipolar splenic diameter was recorded in Class $\mathrm{C}$ with significant difference among the stages $(p=0.424) . P / S$ diameter ratio was found to be maximum in Class $A$ and the minimum ratio was found in Class $C$ with a p-value of 0.023 (Table 2). As the Child-Pugh Class increased, the percentage of patients with oesophageal varices also increased with a maximum in class C $(100 \%)$.

\begin{tabular}{|c|c|c|c|c|}
\hline $\begin{array}{c}\text { Child-Pugh } \\
\text { Classification }\end{array}$ & $\begin{array}{c}\text { A (N=15; } \\
\mathbf{1 0 \% )}\end{array}$ & $\begin{array}{c}\text { B (N=85; } \\
\mathbf{5 6 . 7 \% )}\end{array}$ & $\begin{array}{c}\text { C (N=50; } \\
\mathbf{3 3 . 3 \% )}\end{array}$ & p-Value \\
\hline $\begin{array}{c}\text { Platelet Count } \\
\text { cells/cumm) }\end{array}$ & 140000 & 121764 & 98000 & 0.027 \\
\hline Spleen Diameter (mm) & 128 & 146 & 148 & 0.424 \\
\hline P:S ratio & 1107 & 862 & 602 & 0.023 \\
\hline Oesophageal Varices & 2 & 16 & 10 & \\
\hline \multicolumn{6}{|l}{ Table 2. Parameters According to Child-Pugh Class } \\
\hline
\end{tabular}

Paquet grade of oesophageal varices also worsened with the escalation in Child-Pugh class. Column grading of oesophageal varices also showed worsening with increasing Child-Pugh score with a significant p-value of 0.018 (Table 3).

\begin{tabular}{|c|c|c|c|c|c|c|c|c|c|}
\hline $\begin{array}{c}\text { Child- } \\
\text { Pugh } \\
\text { Class }\end{array}$ & \multirow{2}{*}{$\begin{array}{c}\text { Number of } \\
\text { Subjects }\end{array}$} & \multicolumn{4}{|c|}{$\begin{array}{c}\text { Paquet's Grades of } \\
\text { Oesophageal Varices }\end{array}$} & \multicolumn{3}{c|}{$\begin{array}{c}\text { Oesophageal Varices } \\
\text { Column grading }\end{array}$} \\
\cline { 3 - 11 } & & 0 & I & II & III & IV & Absent & Small & Large \\
\hline A & 15 & 5 & 10 & 0 & 0 & 0 & 5 & 10 & 0 \\
\hline B & 85 & 5 & 10 & 35 & 30 & 5 & 5 & 45 & 35 \\
\hline C & 50 & 0 & 0 & 5 & 45 & 0 & 0 & 5 & 45 \\
\hline \multicolumn{1}{|c|}{ Table 3. Child-Pugh Class, Paquet's Grading System and } \\
Size Grading System \\
\hline
\end{tabular}

The correlation of $\mathrm{P} / \mathrm{S}$ ratio for the presence of oesophageal varices came out to be clinically significant with $\mathrm{p}$-value 0.011 . In the subjects, with $\mathrm{P} / \mathrm{S}$ diameter ratio value $\leq$ 909 (115 subjects), the percentage of larger varices was more. By Paquet grading, $4.35 \%$ of subjects had grade 4 and $65.2 \%$ subjects had grade 3 varices. Grade 1 varices were 
detected in $4.35 \%$ and grade 2 in $26.08 \%$. When size (column) classification was used, $69.6 \%$ of subjects had large varices and $30.4 \%$ had small varices.

In the other subset of subjects with $\mathrm{P} / \mathrm{S}$ ratio $>909$ including 35 subjects, 10 (28.6\%) subjects did not have any oesophageal varices, 15 (42.9\%) had Paquet grade I, II $(28.6 \%)$ had grade II and none had grade III/ IV varices. By size (column) grading out of 35 subjects, 10 (28.5\%) subjects did not have any oesophageal varices. Small oesophageal varices were observed in $25(71.4 \%)$ subjects only. These findings were statistically significant with $\mathrm{p}=0.002$ for Paquet staging and $p=0.001$ for column grading (Table 4 )

\begin{tabular}{|c|c|c|c|c|c|c|c|c|}
\hline \multirow{2}{*}{$\begin{array}{c}\mathbf{P} / \mathbf{S} \\
\text { Diameter }\end{array}$} & \multirow{2}{*}{$\begin{array}{l}\text { Number of } \\
\text { Subjects }\end{array}$} & \multicolumn{2}{|c|}{ Oesophageal Varices } & \multicolumn{5}{|c|}{ Paquet Grading } \\
\hline & & Absent & Present & $\mathbf{0}$ & I & II & III & IV \\
\hline & 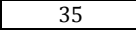 & & & 0 & 5 & 30 & 75 & 5 \\
\hline & & & & U & & 0 & O & \\
\hline $10 \mathrm{tat}$ & & 10 & 170 & 10 & 20 & 40 & 75 & J \\
\hline \multicolumn{9}{|c|}{$\begin{array}{c}\text { Table 4. Correlation of Platelet Count to Spleen Diameter Ratio with } \\
\text { the Presence of Oesophageal Varices and Paquet Grading }\end{array}$} \\
\hline \multicolumn{9}{|c|}{$\begin{array}{l}\text { P value }=0.008, \text { Sensitivity }=100 \%, \text { Specificity }=28.57 \%, \text { Positive Predictive Value } \\
=82.14 \%, \text { Negative Predictive Value }=100 \%\end{array}$} \\
\hline
\end{tabular}

In our study 140 subjects had oesophageal varices out of 150. In these patients, the mean value of $P / S$ ratio was found to be 842 whereas in 10 subjects who did not have varices had the mean value of 1272 . This difference was found to be highly statistically significant $(\mathrm{p}=0.011)$.

\begin{tabular}{|c|c|c|}
\hline Oesophagal Varices & Number of Subjects & P/S Ratio (Mean \pm SD) \\
\hline Present & 140 & $844 \pm 234$ \\
\hline Absent & 10 & $1272 \pm 314$ \\
\hline Total & 150 & $875 \pm 305$ \\
\hline \multicolumn{2}{|c|}{ Table 5. Correlation of Oesophageal Varices with Platelet Count to } \\
Spleen Diameter Ratio \\
\hline
\end{tabular}

\section{DISCUSSION}

The hypothesis proposed for this study was that there exists a correlation between the ratio of platelet count and bipolar spleen diameter for the prediction of oesophageal varices. Based on previous studies, a reference cut off the value of this ratio was taken as 909 and was hypothesized that subjects with a value less than this predictably have oesophageal varices.

A similar trend of a number of subject inclusions was seen in the study by G. H. Sether et al, ${ }^{7}$ who had $13.27 \%$ ChildPugh Class A, 60.18\% Child-Pugh Class B and 26.55\% ChildPugh Class $\mathrm{C}$ subjects out of total 113 patients. Identical subject subsets were included in the study by Zaman et $\mathrm{al}^{5}$ with the maximum being in Child-Pugh class B. Higher number of subjects were reported in Child class $\mathrm{A}$ in the studies by M.H. Chang et $\mathrm{al}^{8}$ and P. Cales et al. ${ }^{9}$

The results of the present study suggested that platelet count reduced as the subject progressed from compensated towards decompensated cirrhosis of the liver (class A to class C). The positive correlation of platelet count reduction to Child-Pugh class progression was seen in our study wherein the Child-Pugh Class A, B and C the mean platelet counts were 140000, 121764 and 98000, respectively (Table 2). Similarly, Garcia- Tsao et al, ${ }^{10}$ Pilette et $\mathrm{al}^{11}$ and K. C. Thromopoulos et $\mathrm{al}^{12}$ in their studies reported a low platelet count in the patients of cirrhosis of the liver. They also found an increase in the magnitude of thrombocytopenia with more pronounced decompensation of the disease process.

In our study, it was observed that as the Child-Pugh class progressed, the value of $\mathrm{P} / \mathrm{S}$ ratio reduced (Table 2). This correlation had high statistical significance $(\mathrm{p}$-value $=0.023)$. The study of Amin $\mathrm{K}$ et $\mathrm{al}^{13}$ had similar results with $\mathrm{P} / \mathrm{S}$ diameter ratio value in Child class A 1137.66, Child class B 728.23 and Child class C 670.84.

In our study, when Child-Pugh class was correlated with the presence of oesophageal varices, the association was found as $100 \%$ in Child-Pugh Class C, $94.1 \%$ in Child-Pugh Class B and $66.7 \%$ in Child-Pugh Class A (Table 5). Similar results were reported by Mahassadi et al ${ }^{14}$ with a higher incidence of oesophageal varices in child class $\mathrm{C}$ whereas Emam et $\mathrm{al}^{15}$, found the incidence of varices to be more in Child-Pugh class A subjects (64.3\%).

In the present study, we found that as the Child-Pugh class increases the grades of oesophageal varices increase as well. Child-Pugh class $C$ subjects were found to have higher grades of varices by both grading systems (Table 3). As per Paquet's grading system grade III, oesophageal varices were found in $0 \%, 35.3 \%$ and $90 \%$ subjects in Child-Pugh class A, B and $\mathrm{C}$ respectively. When graded by size (column) grading, large varices were seen in $0 \%, 41.2 \%$ and $90 \%$ of subjects in Child Class A, B and C respectively. These results were statistically significant for column grading $(\mathrm{p}$-value $=0.018)$. Similarly, Nishaat et al,16 Dib ret al ${ }^{17}$ and Samada et al. ${ }^{18}$ Also reported a higher incidence of large oesophageal varices with decompensated cirrhosis of the liver. Increase in the oesophageal variceal size with the higher Child-Pugh score was reported by Cales, Desmolratetal ${ }^{9}$ as well.

The $\mathrm{P} / \mathrm{S}$ ratio cut off of 909 used in our study was the one determined by Giannini et $\mathrm{al}^{6}$ in predicting large varices. In our study, all the subjects with $\mathrm{P} / \mathrm{S}$ ratio $\leq 909$ had oesophageal varices. This ratio value of 909 was found to be highly statistically significant in predicting the presence of oesophageal varices ( $p$-value 0.008 ).

In our study, the sensitivity of $\mathrm{P} / \mathrm{S}$ ratio for prediction of oesophageal varices was found to be $100 \%$. A similar result was obtained in the studies by Giannini et $\mathrm{al}^{6}(91.5 \%)$ and Sarangapani et al (88.5\%) and slightly lower sensitivity were reported by de Mattos et al ${ }^{19}(77.5 \%)$. The specificity in the present study for this cut off of 909 was $28.57 \%$. Higher values were reported by Sarangapani et al ${ }^{20}(83 \%)$ and Giannini et al $^{6}(67 \%)$ whereas lower by de Mattos et $\mathrm{al}^{19}$ $(45.5 \%)$. The positive predictive value in our study was 82.14\%. Similar values have been obtained by Angela Zambam de Mattos et $\mathrm{al}^{19}(79.5 \%)$, E. Giannini et al ${ }^{6}(87 \%)$, Sarangapani et $\mathrm{al}^{20}(83.5 \%)$ and Schwarzenberger et al ${ }^{21}$ (74\%). The highest positive predictive value was found in a study by Agha et $\mathrm{al}^{22}$ (93.8\%). In our study, the negative predictive value was found to be $100 \%$. Similar results have been reported by Giannini et $\mathrm{al}^{6}(87 \%)$, Sarangapani et $\mathrm{al}^{20}$ (90.5\%) and Schwarzenberger et al 21 (73\%) along with Aghaet $\mathrm{al}^{22}(100 \%)$. A lower negative predictive value was reported by Mattos et $\mathrm{al}^{19}(42.6 \%)$.

Many researchers have predicted different cut off values for this ratio and found different results as well. Baig et $\mathrm{al}^{23}$ reported a cut-off value of 1014 , which gave positive and negative predictive values of $95.4 \%$ and $95.1 \%$, respectively. F. Barrera et al, ${ }^{24}$ in their study of 67 patients with the cut off value 830.8 , found $77.8 \%$ negative predictive value. Makarem et $\mathrm{al}^{25}$ found $100 \%$ sensitivity and $100 \%$ negative predictive 
value for a cut off of 939.7. Barikbin et $\mathrm{al}^{26}$ in their study including 55 subjects had $93 \%$ negative predictive value for a cut off 921 . Similar results were obtained in studies by Emam et $\mathrm{al}^{15}$ (Cut off 900), Agha et $\mathrm{al}^{23}$ (Cut off 571) and Nashaat et $\mathrm{al}^{16}$ (Cut off 820 ). In the study by Amin K. et al ${ }^{13}$ the mean $\mathrm{P} / \mathrm{S}$ ratio for the patients with oesophageal varices was found to be 704.28 and those without varices was 1162.41 . These findings were similar to our study. The proposed hypothesis, that the propensity for finding oesophageal varices increases as the ratio reduces further, stands true in these studies.

\section{CONCLUSIONS}

As Child-Pugh class progressed, there was also a fall in $\mathrm{P} / \mathrm{S}$ ratio which was statistically highly significant ( $\mathrm{p}$-value= 0.023). Further, it was also seen that oesophageal variceal grading also worsened with increasing Child-Pugh class. All the subjects with $\mathrm{P} / \mathrm{S}$ ratio $\leq 909$ had oesophageal varices. The value of 909 was found to be statistically highly significant in predicting the presence of oesophageal varices ( $p$-value $=0.008)$. The sensitivity of $\mathrm{P} / \mathrm{S}$ ratio for the screening of oesophageal varices was found to be $100 \%$. The specificity in the present study for this cut off of 909 was $28.57 \%$. Thus, it can be concluded that a cut off value of 909 for $\mathrm{P} / \mathrm{S}$ ratio can be taken as a non-invasive marker to differentiate high- and low-risk patients in screening oesophageal varices in patients of cirrhosis of liver.

\section{REFERENCES}

[1] Fauci A, Braunwald E, Kasper D, et al. Harrison's Principle of Internal Medicine. Chap - 308. Cirrhosis and its complications. 18 ${ }^{\text {th }}$ edn. McGraw-Hill Education 2011: p. 2592.

[2] Joshi PH. Chronic Hepatitis 'B'. Bombay Hospital Journal 1996;3804(October Special):701-12.

[3] Neogi DK. Prevalence of HCV Infection among patients of chronic active hepatitis and cirrhosis cases in Calcutta. Indian Journal of Medical Microbiology 2001;19(1):46-7.

[4] Bapat S, Joshi D, Naik SS, et al. Hepatitis B immunization in adolescent girls. Indian Pediatr 2001;38(10):1160-2.

[5] Zaman A, Becker T, Lapidus J, et al. Risk factors for the presence of varices in cirrhotic patients without a history of variceal haemorrhage. Arch Intern Med 2001;161(21):2564-70.

[6] Giannini E, Botta F, Borro P, et al. Platelet count/spleen diameter ratio: proposal and validation of a non-invasive parameter to predict the presence of esophageal varices in patients with liver cirrhosis. Gut 2003;52(8):1200-5.

[7] Sethar GH, Ahmed R, Rathi SK, et al. Platelet count/splenic size ratio: a parameter to predict the presence of esophageal varices in cirrhotics. J Coll Physicians Surg Pak 2006;16(3):183-6.

[8] Chang MH, Sohn JH, Kim TY, et al. Non endoscopic predictors of large esophageal varices in patients with liver cirrhosis. Korean J Gastroenterol 2007;49(6):37683.

[9] Cales P, Desmorat H, Vinel JP, et al. Incidence of large esophageal varices in patients with cirrhosis: application of prophylaxis of first bleeding. Gut 1990;31(11):1298 302.

[10] Garcia-Tsao G, Escorsell A, Zakko M, Predicting the presence of significant portal hypertension and varices in compensated cirrhotic patients. Hepatology 1997;26:927-30.

[11] Pilette C, Oberti F, Aube C, et al. Non-invasive diagnosis of esophageal varices in chronic liver disease. J Hepatol 1999;31(5):867-73.

[12] Thomopoulos KC, Labropoulou-Karatza C, Mimidis KP, et al. Non-Invasive predictors of the presence of large esophageal varices in patients with cirrhosis. Dig and Liver Dis 2003;35(7):473-8.

[13] Amin K, Muhammad D, Anjwn A, et al. Platelet count to spleen diameter ratio as a predictor of esophageal varices in the patients of liver cirrhosis due to Hepatitis C virus. JUMDC 2012;3(1):6-11.

[14] Mahassadi AK, Bathaix FY, Assi C, et al. Usefulness of non-invasive predictors of oesophageal varices in Black African cirrhotic patients in Cote D'ivoire (West Africa). Article ID 216390. Gastroenterology Research and Practice 2012;(2012):1-10.

[15] Emam E, Ramadan A, Badway M, et al. Prediction of oesophageal varices in patients with compensated cirrhosis: a novel scoring system. Arab $\mathrm{J}$ of Gastroenterology 2009;10(4):129-34.

[16] Nashaat EH, Abd-Elaziz H, Sabry M, et al. Non-endoscopic predictors of esophageal varices and portal hypertensive gastropathy. Nature and Science 2010;8(6):43-50.

[17] Dib N, Konate A, Oberti F, et al. Non-invasive diagnosis of portal hypertension in cirrhosis. Application to primary prevention of varices. Gastroenterol Clin Biol 2005;29(10):975-87.

[18] Samada M, Hernandez JC, Barroso L, et al. Identification de factore de riesgode presencia de varices esofagicas en pacientes con cirrosis hepatica. Revista Cubana de Medicina Militar 2008;37(1):5-12.

[19] De Mattos AZ, de Mattos AA, Vianna FF, et al. Platelet count/spleen diameter ratio: analysis of its capacity as a predictor of the existence of esophageal varices. Arq Gastroenterol Sao Paulo 2010;47(3):275-8.

[20] Sarangapani A, Shanmugam C, Kalyanasundaram M, et al. Non-invasive prediction of large esophageal varices in chronic liver disease patients. Saudi J Gastroenterol 2010;16(1):38-42.

[21] Schwarzenberger E, Meyer T, Golla V, et al. Utilization of platelet count spleen diameter ratio in predicting the presence of esophageal varices in patients with cirrhosis. J Clin Gastroenterol 2010;44(2):146-50.

[22] Agha A, Anwar E, Bashir K, et al. External validation of the platelet count/spleen diameter ratio for the diagnosis of esophageal varices in hepatitis C virusrelated cirrhosis. Dig Dis Sci 2009;54(3):654-60.

[23] Baig WW, Nagaraja MV, Varma M, et al. Platelet count to spleen diameter ratio for the diagnosis of esophageal varices: Is it feasible? Can J Gastroenterol 2008;22(10):825-8.

[24] Barrera F, Riquelme A, Soza A, et al. Platelet count/spleen diameter ratio for non-invasive prediction of high risk esophageal varices in cirrhotic patients. Annals of Hepatology 2009;8(4):325-30. 
[25] Abu El Makarem MA, Shatat ME, Shaker Y, et al. Platelet count/ bipolar spleen diameter ratio for the prediction of esophageal varices: the special Egyptian situation: Noninvasive prediction of esophageal varices. Hepat Mon 2011;11(4):278-84.
[26] Barikbin R, Hekmatnia A, Omidifar N, et al. Prediction severity of esophageal varices: a new cut off point for Platelet count/ spleen diameter ratio. Minerva Gastroenterol Dietol 201056(1):1-6. 